CIENCIAY SOCIEDAD

Volumen XXXIV, Número 2

Abril-Junio 2009

\title{
MONOGRAFÍAS, RESEÑAS Y EVENTOS
}




\section{CIENCIAY SOCIEDAD \\ Volumen XXXIV, Número 2 \\ Abril-Junio 2009}

INNOVACIÓN DEL TURISMO

\section{María Concepción Verona Martel*}

Título del libro: Innovación del turismo.

Autores: Javier Gallego Llorca y Javier Osorio Acosta.

Editorial: Fundació per a la Universitat Oberta de Catalunya.

ISBN: 84-9707-688-5.

Año de publicación: 2006.

Lugar de publicación: Barcelona. España.

Páginas: 322 páginas.

Índice: 1. La innovación; 2. Difusión de las innovaciones; 3. Innovación y competitividad; 4. Características organizativas en la innovación; 5. Los recursos humanos en la innovación; 6 . El rol de la tecnología en la innovación; 7. La innovación en el sector competitivo; 8. La innovación en las actividades internas; 9 . Reingeniería de procesos.

Breve resumen de su contenido: el desarrollo que el turismo, como actividad económica, ha experimentado en los últimos tiempos no tiene parangón en ninguna otra área de la esfera humana. En relativamente pocas décadas se ha pasado de unos niveles prácticamente testimoniales de lo que puede denominarse actividad turística a convertirse en la primera industria mundial, generando flujos monetarios, de recursos y humanos como no lo ha hecho cualquier otra actividad humana en el pasado.

* Universidad de Las Palmas, Gran Canaria, España.

E-mail: cverona@defc.ulpgc.es 
Son muchos los factores que han contribuido a esta situación y también son numerosas las variables que confluyen a la hora de comprender e intentar sistematizar la naturaleza del turismo y de su gestión. De cualquier forma, resulta innegable que el ritmo de cambios y de aparición de nuevas ofertas y destinos turísticos refleja la realidad de un sector en permanente cambio para adaptarse a nuevos retos y necesidades, en un mercado de carácter global y para unos clientes y trabajadores cada vez más exigentes en sus demandas.

No cabe duda, entonces, que el sector turístico se caracteriza actualmente por ser una actividad sometida a una continua innovación, con ciclos de vida, tanto de productos como de servicios, cada vez más cortos, que obligan a los agentes participantes a modificar o introducir nuevas alternativas a la forma habitual de trabajo con objeto de mantener o mejorar la posición competitiva.

En este sentido, el libro de Innovación del Turismo se ha escrito con la filosofía de ofrecer una visión integradora de lo que constituye el proceso de innovación en el ámbito del turismo, las variables que afectan a la misma, así como las técnicas y herramientas que pueden facilitar la identificación y desarrollo de innovaciones. Por esta razón se ha intentando alcanzar un equilibrio apropiado entre conceptos teóricos y herramientas prácticas, que permita al lector dominar ambas dimensiones, con objeto de que se complementen y favorezca la consecución de los mejores resultados posibles en su futura actividad profesional. El libro está enfocado principalmente hacia aquellas personas que, por su talante y motivación, esperan poder aportar dosis de mejora en las organizaciones turísticas en las que van a desempeñar su actividad, por la vía de propuestas innovadoras en los productos o procesos ofertados.

Con el fin de que el lector adquiera las habilidades y conocimientos que se pretenden transmitir con este libro los contenidos han sido distribuidos en un total de nueve capítulos agrupados en tres bloques homogéneos. De forma general, los objetivos que se han pretendido alcanzar en la redacción del texto han sido los siguientes: (a) Explicar los conceptos básicos relacionados con la innovación en las organizaciones; (b) Desmitificar las ideas y concepciones erróneas sobre la innovación; (c) Entender la importancia de la innovación en el marco de competitividad que domina actualmente en el sector turístico internacional; (d) Dar a conocer algunos mecanismos de difusión de la innovación y de las estrategias de innovación en ámbitos competitivos; (e) Contemplar la problemática de la 
innovación como un proceso multidisciplinar; (f) Integrar nociones y conocimientos propios de otros ámbitos, como son la Organización y Administración de Empresas, Operaciones y Procesos de Producción, Recursos Humanos, Sociedad del Conocimiento y las Tecnologías de la Información; (g) Mostrar la utilización de herramientas prácticas que faciliten el desarrollo de ideas innovadoras; (h) Contextualizar la innovación en el entorno competitivo en el que tiene lugar; (i) Identificar fortalezas y debilidades internas a las que dar respuesta mediante la innovación; (j) Interpretar las tendencias que se están produciendo en el sector turístico en materia de innovación.

Recibido: $17 / 10 / 08$

Aprobado: 20/02/09 


\section{Innovación del turismo}

Javier Gallego Llorca Javier Osorio Acosta

XP04/85026/01751

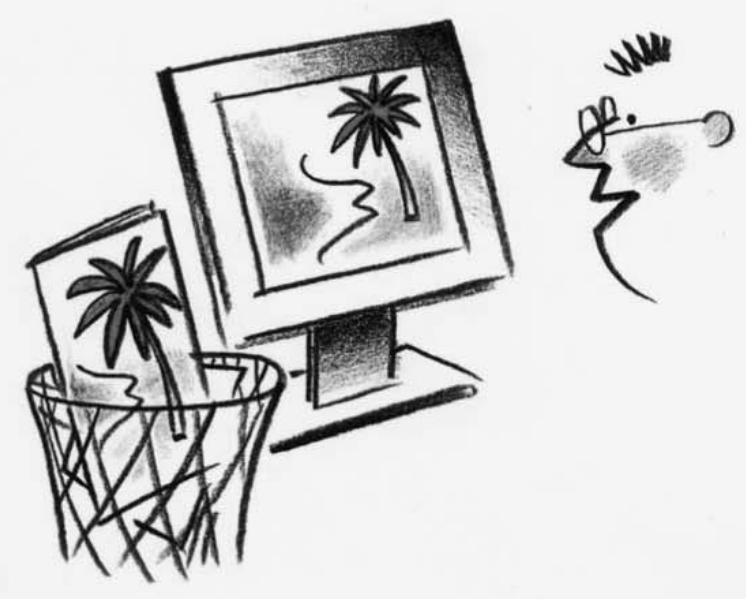

\section{$\square$ UOC \\ www.uoc.edu}

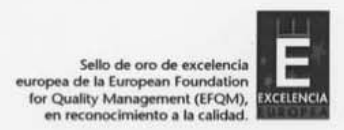

